\title{
Humor gráfico: abordajes del COVID-19 en el diario El Universo de Ecuador
}

\section{Graphic humour: approaches of COVID-19 in Ecuadorian newspaper El Universo}

Recibido: 01/04/2020

Aceptado: 15/06/2020

Publicado: 26/06/2020
Julio Bravo Mancero

jbravo@unach.edu.ec

https://orcid.org/0000-0002-4468-9247

Universidad Nacional de Chimborazo (Ecuador)

Fermín Galindo Arranz fermin.galindo@usc.es

https://orcid.org/0000-0002-2764-2121

Universidad Santiago de Compostela (España)

Resumen: El artículo investiga los abordajes utilizados por el caricaturista Bonil del diario El Universo (Ecuador) para representar el avance de la pandemia provocada por el COVID-19. Se empleó una metodología mixta (cualitativa y cuantitativa) plasmada en la revisión documental, el análisis de contenido y análisis del discurso de 25 viñetas publicadas entre el 13 de marzo y 10 de abril de 2020. Los resultados demostraron que los contenidos se difundieron desde los siguientes ejes: salud, economía, política, corrupción, sociedad y tecnología. Lo icónico y lo verbal, mediante la construcción de metáforas visuales, sirvieron para que la opinión pública advirtiera las secuelas que deja el virus y la escenificación de los espacios de poder, dominación y desigualdad que puso en evidencia la debilidad de la sociedad ecuatoriana. 
Palabras clave: Humor periodístico, Caricatura, Abordajes, Sociedad, Pandemia, COVID-19.

Abstract: This paper investigates the coverage used by cartoonist Bonil, in ecuadorian newspaper El Universo, to represent the advance of pandemic COVID-19. Mixed methodology was used: qualitative and quantitative, through the documentary review, content analysis and discourse analysis, to 25 cartoons, published between March 13 and April 10, 2020. The results showed contents were disseminated into the following axes: Health, Economy, Politics, Corruption, Society and Technology. Iconic and verbal elements, through the construction of visual metaphors, served to warn public opinion of pandemic consequences as well as to watch spaces of power, domination and inequality, highlighted Ecuadorian society weakness.

Key words: Journalistic humor, Cartoon, Coverage, Society, Pandemic, COVID-19.

\section{Introducción}

El presente artículo analiza el tratamiento en torno al COVID-19 en las caricaturas publicadas por Xavier Bonilla (Bonil), en el diario El Universo, de Ecuador. Asimismo, se determina la manera en que sus dibujos advierten la importancia de la actuación oportuna, el manejo de la información sobre los contagios y las muertes, la protección de las personas, la importancia de no automedicarse y la conciencia social de que la emergencia sanitaria responsabiliza a todos. En ese sentido, el Humor gráfico es utilizado como herramienta para generar conciencia social ante la amenaza del virus.

La metodología fue mixta (cualitativa y cuantitativa). Las técnicas empleadas fueron la revisión documental, el análisis de contenido y el análisis crítico del discurso, todas estas enfocadas en las 25 viñetas publicadas en el rotativo guayaquileño entre el 13 de marzo y el 10 abril de este año. El análisis y la aproximación sobre los trabajos difundidos por Bonil, sirvió para evaluar:

- La observación de los ejes temáticos y la procedencia.

- La identificación de la concepción icónica y verbal.

- La definición de los actores y los niveles de interrelación entre ellos. 
- La construcción de metáforas visuales para recrear la realidad.

- La determinación de los ambientes de las narrativas.

- La importancia del uso del lenguaje, el discurso y la interacción verbal.

- Los escenarios de poder, dominación y desigualdad.

- La actuación de los miembros del grupo, sus acciones-procesos y la estructura social.

Se pudo demostrar que este género periodístico no solo sirvió para orientar a la opinión pública, sino también para recrear la vida cotidiana en medio de una emergencia sanitaria. Los hallazgos sirvieron para reivindicar el rol de la viñeta como instrumento de construcción de conciencia social.

\section{La vida cotidiana desde el humor gráfico}

\subsection{La práctica del periodismo}

El diario El Universo, de Ecuador, incorporó a su agenda de información y opinión, desde que se conocieron los primeros casos en el mundo, temas relacionados con el COVID-19. Poco a poco, fue incrementando el número de contenidos publicados: de 2 por día hasta llegar a 19. El 24 de febrero de 2020 se evidenció el primer cambio en la difusión, debido a que una mujer (proveniente de Europa) dio positivo el día anterior y las alertas sanitarias se encendieron. En las semanas siguientes aumentó el flujo de noticias, crónicas, reportajes, editoriales, artículos de opinión y caricaturas.

El periodismo es una actividad que consiste en obtener información, contrastarla, comprobarla y verificarla, con rigor, para presentarla en forma de contenidos en los medios de comunicación masiva (Bravo, 2012), haciendo que este proceso requiera efectiva preparación para responder las necesidades de las audiencias. Gronemeyer (2003) lo define como "una vocación, como un llamado y compromiso de resguardar y potenciar especialmente unos determinados valores en la comunidad humana" (p. 48). Rivera-Betancur (2008) señala que, en la actualidad, el ejercicio periodístico tiene un reto importante: hacer frente a la irrupción pública de las voces de los ciudadanos.

Sin el periodismo ejercido desde los medios, las personas no tendrían oportunidad de conocer los hitos que impactarán en su realidad. Un estudio realiza- 
do por la Organización de las Naciones Unidas para la Educación, la Ciencia y la Cultura (UNESCO, 2007) indica que el periodismo desempeña diversas funciones en la sociedad contemporánea, proporciona información, análisis y comentario de los hechos de actualidad, brindando la posibilidad de reflexionar sobre lo que ocurre en el entorno de los individuos.

Rincón (2017) precisa que el periodismo era "esa práctica democrática que ponía en juego la libertad de expresión para generar una opinión pública diversa y plural y molestar a los poderes" (p. 9). Precisamente, incomodar a la función pública puede ser interpretada desde dos posiciones: una, próxima a contar la verdad que no quieren que se difunda, porque hará tambalear a quienes ostentan el poder; y la otra, decir lo que ocurre o negociarlo para beneficiarse de prebendas. La primera opción debe convertirse en la opción para desarrollarse en esta profesión y obtener esa tan necesaria credibilidad.

Existe otra disyuntiva apuntada por Siegel (2017): la selección de los hechos responde a la coherencia de que la historia que se contará está subordinada a los intereses del formato periodístico y del medio: si no lo está, nada se publicará; cuestión de línea editorial o de conveniencia. Esta acción puede ser la pared contra la que choque la expectativa colectiva por conocer lo que ocurrió, qué características tuvo, cómo fue y qué consecuencias tendrá. Resulta lamentable que esta perspectiva (regida por la vorágine de la actualidad noticiosa) sea una de las más predominantes para contar las historias.

En tiempo de crisis, como los contemporáneos, los medios masivos (trasladados a las plataformas digitales) han empezado a recuperar la hegemonía y el respaldo de la opinión pública, esta última con la urgencia de enterarse de lo que ocurre frente a una emergencia; los diarios volvieron a ser esa vía que permite transparentar los datos que el sector oficial olvidó hacerlo.

\subsection{El uso del humor gráfico en el periodismo}

Conde (2005) destaca el valor del periodismo dibujado en las sociedades porque (como arte expresivo y comunicador) permite contar la realidad con criterio profesional, para que la opinión pública tome partido a favor o en contra de un hecho. En el pasado, "la caricatura era un arte en desarrollo y contribuyó a la formación del humorismo gráfico, casi tanto como las técnicas de 
las artes de imprenta" (p. 118). Y, pese a quienes opinan lo contrario, se ha sostenido como una atractiva opción para informarse y opinar.

Los medios europeos, norteamericanos y latinoamericanos no tardaron en identificar a la caricatura como un arte próximo al humor gráfico dentro el periodismo para (con perspicacia) retratar a los actores de la sociedad. Como se presentará en los resultados de este artículo, el humor gráfico toma como referencia tres series informacionales que irán juntas: la icónica denotada, la lingüística y la icónica connotada.

Lemos (2011) y Antezana (2009) aseveran que el humor hace más comprensible la transmisión de un discurso: no se necesita recurrir a profundas estrategias argumentativas para enfocar el tema y que la gente lo prefiera. Fernández (2015) añade que utiliza métodos que, en la actualidad, pueden reforzar estereotipos y prejuicios, de género tan de moda en la violencia simbólica. En los medios, el espacio humorístico no escapa de la realidad comunicacional, convertida en la alternativa para las audiencias que, a través de este, se hace un criterio y construye su verdad (Rodríguez-Pastene, González \& Messenet, 2019). Ahumada (2019) precisa que

una caricatura hace uso de elementos visuales, en donde representa a un personaje o a varios, cuyas características le permiten al lector identificar con facilidad a quien se está refiriendo, sin olvidar que esta tiene como principal objetivo la crítica. (p. 10)

María Ronderos (citada en Arias, 2008) manifiesta que el humor gráfico, “tiene la contundencia de poder sintetizar en una frase y una viñeta un hecho que le toma varios párrafos a un redactor o a un columnista de opinión" (p. 111). Aquí radica su trascendencia frente a otro tipo de contenidos.

\subsection{Opinión pública}

Consideramos vital establecer una definición de la opinión pública, a fin que los lectores encuentren una dimensión de lo que representa para el humor gráfico. Para Muñiz (2017) se la ha conceptualizado "como la suma o el agregado de las opiniones individuales, las que son mantenidas por los ciudadanos acerca de los asuntos o temáticas que se presentan en la esfera pública" (p. 10). González-Domínguez (2017) se aproxima a una construcción de signifi- 
cados, encasillándola como "el resultado de la generación de discursividad, a partir de la discusión de un público que hace uso de la razón ... La opinión pública no es medible en número, sino que posee la cualidad de poder argumentativo, capaz de decidir acciones" (p. 26). Hegel (2006) considera que

la libertad subjetiva formal es para los individuos la de expresar sus propios juicios, sus propias opiniones y sus consejos sobre los asuntos públicos que tiene su manifestación en el conjunto de fenómenos que llamamos opinión pública. En ésta, lo universal en sí y para sí, lo substancial y lo verdadero están asociados a sus contrarios: lo particular para sí, la particularidad de la opinión de las masas. (p. 173)

Es por estas razones que hemos incluido a la opinión pública en este trabajo para que sea dimensionada desde la perspectiva del humor gráfico como acto emergente de un medio para vincularse con su audiencia.

\section{Objetivo, metodología y población}

Se formuló como objetivo determinar cómo diario El Universo, a través del humor periodístico, abordó a la pandemia del Convid-19. La presente investigación es de tipo mixta (cuantitativa-cualitativa), empleando las técnicas de la revisión documental, el análisis de contenido y el análisis crítico del discurso, así como la ficha de revisión y las matrices de análisis como instrumentos.

- Revisión documental: permitió identificar los aportes de las caricaturas publicadas por el diario ecuatoriano. Valencia (citado en Bravo et al., 2019b) cataloga como una técnica primordial. Fue el cimiento sobre el que se construyó la aproximación, ya que sin ella la recolección de información no habría alcanzado el fin planeado. Hurtado (2010) también la considera una técnica vital. Es decir, a partir de la publicación de las viñetas (caricaturas) se contó a los lectores la gravedad de la pandemia usando el humor periodístico.

- Análisis de contenido: Monje (2011) la considera una técnica que recrea la realidad a través de publicaciones realizadas en medios masivos de comunicación. Según Hernández (citado en Fernández, 2002), "es una técnica muy útil para analizar los procesos de comunicación en muy diversos contextos”. Navarro \& Díaz (1994) la de- 
finen "como un conjunto de procedimientos que tienen como objetivo la producción de un meta-texto analítico en el que se representa el corpus textual de manera transformada" (pp. 181-182).

- Análisis Crítico del Discurso (ACD): para Van Dijk (2016, p. 204), expresa cómo el abuso de poder y la desigualdad social se representan, reproducen, legitiman y resisten en el texto y en el habla para contextos sociales y políticos. Fairclough \& Wodak (citados en Van Dijk, 2016) sostienen que "aborda problemáticas sociales" (p. 205), entendiendo que las relaciones de poder son discursivas y que el discurso, por tanto, tiene implicancias ideológicas.

La investigación es cualitativa, puesto que permitió recoger datos y describir situaciones de interés general (Gómez et al., 2010) y al basarse en una lógica y en un proceso inductivo. Del mismo modo, el proceso investigativo es cuantitativo porque utiliza diversos procedimientos, métodos y herramientas para atender una problemática (Salinas \& Cárdenas, 2009, p. 100).

La población observada corresponde a 25 caricaturas publicadas en la página de opinión del rotativo guayaquileño, entre el 13 de marzo al 10 de abril de 2020. La autoría corresponde a Xavier Bonilla, quien emplea el seudónimo de "Bonil".

El trabajo se efectuó en tres etapas (ver Figura 1). A la primera (documental) le correspondió la revisión de los 25 ejemplares del período estudiado; luego la recuperación de las caricaturas que aparecieron en la página de opinión; la clasificación de los materiales (en carpetas y por fechas) para facilitar su análisis.

\section{Figura 1}

Esquema de tratamiento documental

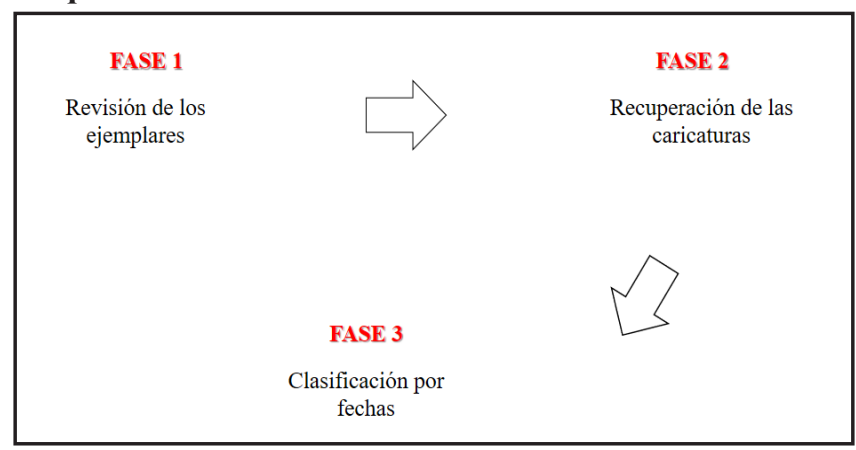

Nota: Elaboración propia. 
La segunda (análisis de contenido) tuvo cinco fases: recuperación de las caricaturas del archivo fechado; aplicación de la matriz de análisis a las 25 caricaturas publicadas en marzo y abril por diario El Universo; clasificación por ejes temáticos y procedencia; jerarquización, selección y valoración de la información obtenida y el establecimiento de las categorías y subcategorías; así como la redacción de los hallazgos para ubicarla en los resultados y su discusión.

La ficha diseñada tuvo las siguientes características:

- Datos generales: fecha y hora de análisis, fecha de publicación de la caricatura y observaciones que sirvieron para contextualizar los hechos que se contaron; categorías y subcategorías.

- Aspecto técnico: temática ("salud", "tecnología", "economía", "corrupción", "sociedad", "violencia familiar"); procedencia (local, nacional e internacional); código icónico (representación con el dibujo); título y discurso (cómo se presenta la historia); actores (¿quiénes están representados?); gestos y expresiones; metáfora visual (qué se quiere mostrar); ambiente (lugar de desenvolvimiento); plano (general, medio, detalle, etc.); color; lenguaje verbal: ¿qué dice? (relato hecho por el caricaturista) y ¿cómo lo dice? (interpretación de los investigadores).

La tercera fase (ACD) tuvo un procedimiento similar al de contenido. Sin embargo, el instrumento utilizado reúne otras características basada en la propuesta de Van Dijk (2016), que comprende los niveles micro y macro. Su estructura es la siguiente:

- Encabezado: que sugiere datos como medio, fecha de publicación y análisis, tipo de contenido, nombre del investigador y observaciones, categorías y subcategorías

- Nivel micro: contiene el uso del lenguaje, discurso e interacción verbal, ¿qué dice?;

- Atención quién está dirigido: miembros del grupo, estructura social, acciones-procesos.

- Cognición-social.

- Nivel macro: que responde al ¿cómo lo dice?, si ejerce poder, dominación y desigualdad. 
Finalmente, los datos fueron codificados y la información fue cuantificada y cualificada para ser presentada en texto, tablas y representaciones gráficas, debidamente ordenadas y organizadas, tal como aparecen en el siguiente apartado.

\section{Resultados}

\subsection{Análisis de contenido}

A continuación, se exponen los descubrimientos sobre los abordajes del COVID-19 en las caricaturas publicadas por Bonil, en el diario El Universo durante los meses en que los ciudadanos ecuatorianos se encontraban en confinamiento. Para una mejor compresión, se distinguen atributos cuantitativos y cualitativos, consignados en tablas y representaciones gráficas, provenientes de la aplicación de las fichas de análisis. La diferenciación permitirá una mejor comprensión.

\subsubsection{Atributos cuantitativos}

La matriz utilizada para la recolección de información permitió cuantificar los ejes temáticos y la procedencia. La Figura 2, resume los ejes desde los cuales se orientó la opinión sobre la pandemia.

\section{Figura 2}

Ejes temáticos de las caricaturas de Bonil

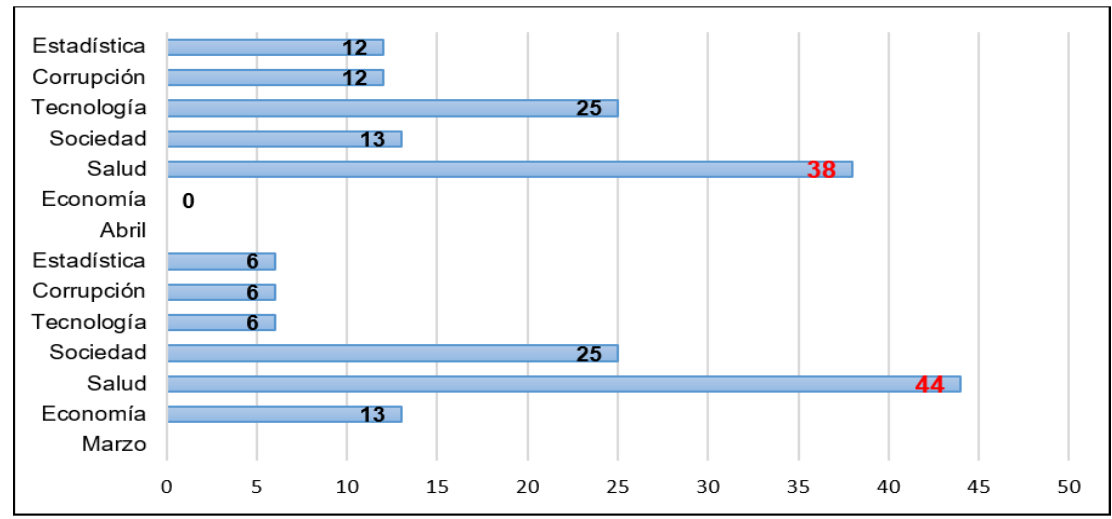

Nota: Elaboración propia, basada en los ejemplares del diario El Universo (13/III/2020-10/IV/2020). 
Como puede apreciarse, la propuesta temática de salud presenta mayor porcentaje de caricaturas durante los meses observados ( $44 \%$ en marzo y $38 \%$ en abril). Al usarse el humor se orientó a la opinión pública sobre la importancia del uso de materiales de protección como mascarillas, guantes, gorro, gafas y vestimenta especial, así como de la importancia del lavado de las manos y no automedicarse. Así se publicó “¡Otra vez oliendo a alcohol!” (Figura 3), una viñeta en la que dos manos interactúan, una representa a la mujer y la otra al marido, en evidente reclamo.

\section{Figura 3}

Caricatura de Bonil: “;Otra vez oliendo a alcohol!“"

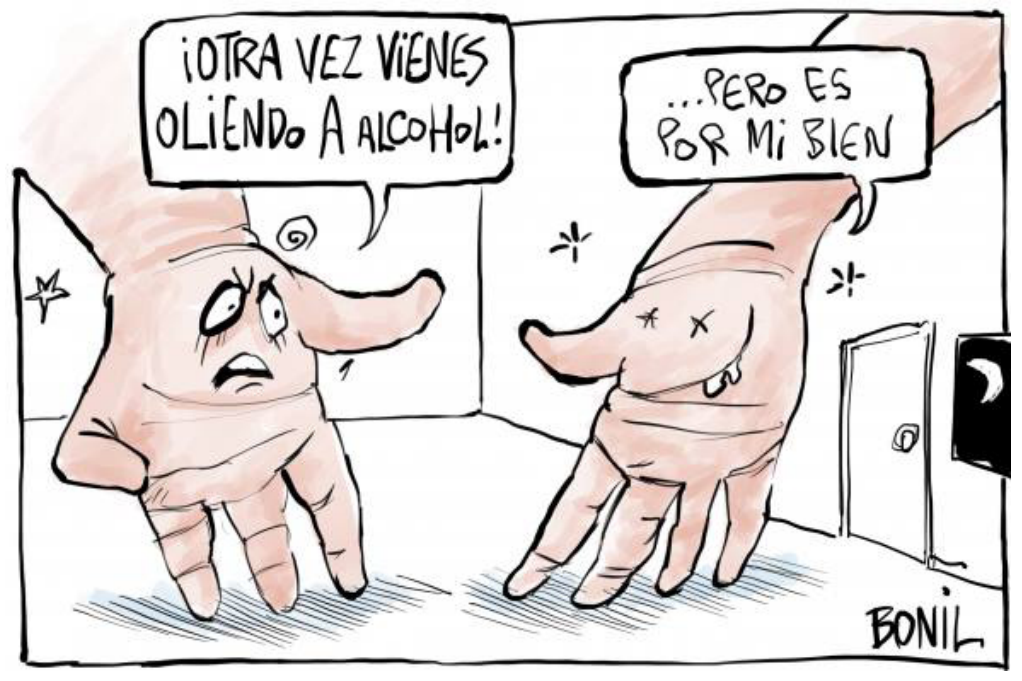

Nota: Diario El Universo (14/III/2020).

Durante marzo ("Sociedad") y en abril ("Tecnología") compartieron el 25\% de difusión. Los temas sociales estuvieron vinculados con la convivencia en familia, el alejamiento entre amigos y la participación en actividades guardando la distancia; los tecnológicos, abordaron el consumo de noticias falsas (fake news) y los consejos que llegan mediante la telefonía móvil para el cuidado de la salud de las personas. Aparecieron, en menor proporción, publicaciones sobre economía (costo y abastecimiento de productos de primera necesidad); estadísticas del número de contagiados y muertos; $\mathrm{y}$, corrupción. ${ }^{1}$

1. Bonil fue un opositor acérrimo de Correa: incluso enfrentó cargos judiciales por sus publicaciones. La crisis y el enfoque desde el medio en el que trabaja fue aprovechado para achacar al ex presidente la responsabilidad de que no existan recursos para atender la emergencia. 
Este último tema se analizará por separado, en la visión de la intencionalidad, porque se relaciona con la acusación directa al expresidente Rafael Correa del despilfarro de recursos que habrían servido para afrontar la crisis sanitaria y visibiliza su sentencia a ocho años de cárcel por sobornos.

Con relación a la procedencia, la Figura 4, demuestra que prevaleció el criterio nacional (57\% en marzo y $78 \%$ en abril). Las caricaturas usaron este criterio para demostrar lo que sucedía en Ecuador; luego, lo internacional $(37 \%$ y $22 \%)$; y, en menor proporción lo local (solo apareció durante marzo $(6 \%)$.

\section{Figura 4}

\section{Procedencia de las caricaturas}

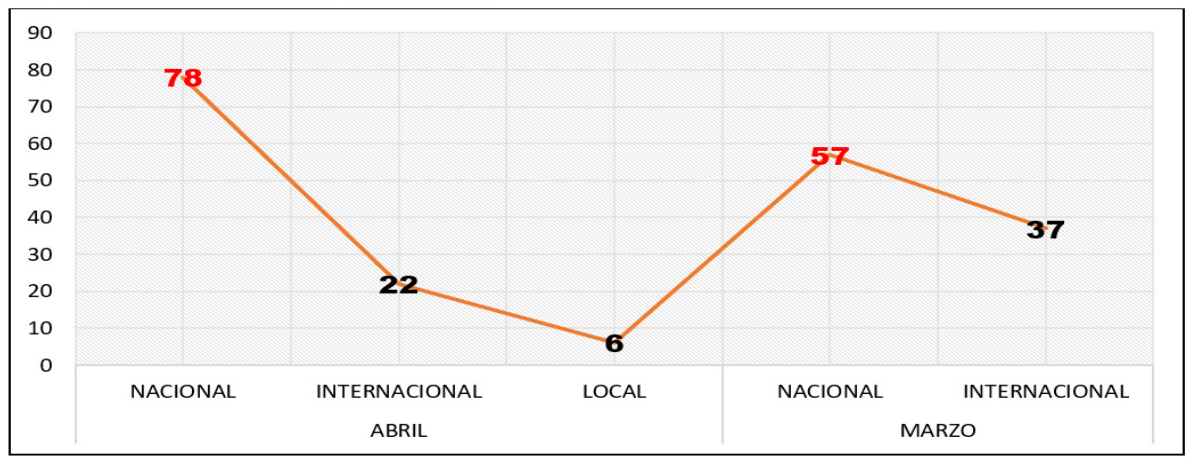

Nota: Elaboración propia, basada en los ejemplares del diario El Universo (13/III/2020-10/IV/2020).

Bajo este criterio, se citan como ejemplo dos caricaturas (Figuras 5 y 6): una sobre la orden dada por la alcaldesa Cynthia Viteri, de bloquear la pista del aeropuerto de Guayaquil para que no aterrice un avión de la compañía Iberia (procedente de Madrid) para repatriar ciudadanos españoles (Figura 5) y la alegoría de la muerte, que se acerca a las puertas de los hogares (Figura 6). 
Figuras 5 y 6

Caricaturas de Bonil: “¿Estilo Jaime... Vargas?” y “Ustedes aquí no entran!”

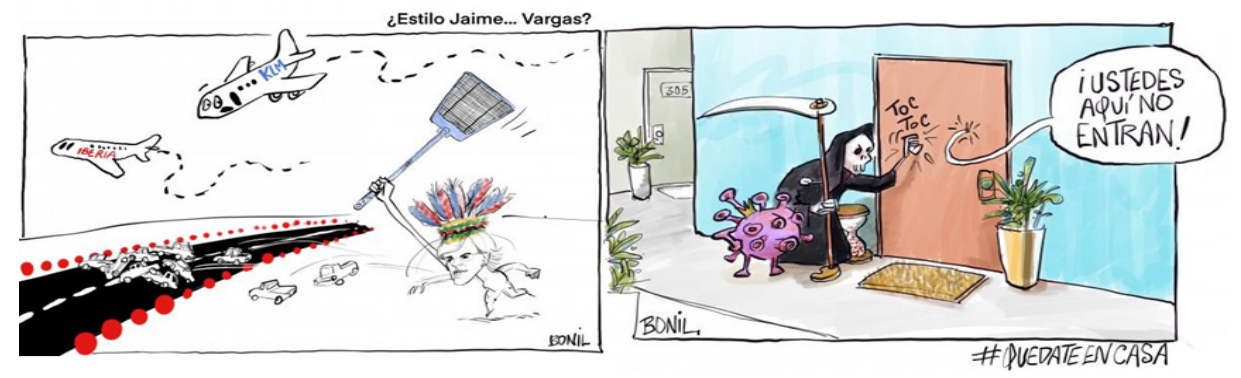

Nota: Diario El Universo (20/III/2020 y 17/III/2020).

\subsubsection{Atributos cualitativos}

Dichos atributos permitieron la comprensión de las opiniones realizadas por el caricaturista y los criterios para presentar historias mediante el humor gráfico; la identificación de los elementos icónicos en los dibujos; la selección de los actores y el nivel de interacción; la gesticulación y expresión para la conformación de la metáfora visual; y la utilización de los ambientes en los que se desenvuelve la narrativa, los planos y el color.

En la Tabla 1, se encuentran títulos representativos, según los ejes temáticos expuestos en la dimensión cuantitativa y en el discurso empleado. Están acompañados por otro de los criterios considerados para el análisis: el uso del lenguaje que considera el ¿qué dice? y el ¿cómo lo dice?, subrayándose ese segundo aspecto en la presentación de los datos. 
Tabla 1

Elementos discursivos usados en las caricaturas

\begin{tabular}{|c|c|c|c|}
\hline $\begin{array}{c}\text { EJE } \\
\text { TEMÁTICO }\end{array}$ & TÍTULO & DISCURSO & $\begin{array}{c}\text { LENGUAJE VERBAL } \\
\text { ¿CÓMO LO DICE? }\end{array}$ \\
\hline Salud & $\begin{array}{l}\text { "Nuestro duelo } \\
\text { colectivo" }\end{array}$ & $\begin{array}{l}\text { Un grupo de personas camina } \\
\text { hacia el cementerio con un } \\
\text { féretro gigante que representa } \\
\text { la cantidad de muertos por la } \\
\text { pandemia, sin que haya una } \\
\text { vacuna para enfrentarla. }\end{array}$ & $\begin{array}{l}\text { Pone énfasis en que el número de } \\
\text { muertos supera las expectativas. } \\
\text { El ataúd enorme dimensiona la } \\
\text { realidad de las defunciones. }\end{array}$ \\
\hline Economía & $\begin{array}{l}\text { "Tiene } \\
\text { pendejitis..." }\end{array}$ & $\begin{array}{l}\text { Un esposo toma precauciones } \\
\text { innecesarias, todavía, frente a } \\
\text { la crisis. Aparece con un carro } \\
\text { lleno de supermercado. }\end{array}$ & $\begin{array}{l}\text { Presenta la temática con ironía, } \\
\text { deja tres puntos suspensivos para } \\
\text { que los lectores saquen sus con- } \\
\text { clusiones, de si el abastecimiento } \\
\text { fue necesario o no. }\end{array}$ \\
\hline Estadísticas & $\begin{array}{l}\text { "Las verdaderas } \\
\text { cifras las } \\
\text { conozco yo..." }\end{array}$ & $\begin{array}{l}\text { El virus aparece sentado con } \\
\text { actitud desafiante frente a los } \\
\text { contagios y muertes que } \\
\text { ocasionó en el mundo. }\end{array}$ & $\begin{array}{l}\text { Ante la falta de difusión de } \\
\text { las cifras reales de contagios y } \\
\text { muertes, en el Ecuador, el virus } \\
\text { se burla de la ineficiencia de los } \\
\text { encargados de los datos. }\end{array}$ \\
\hline Sociedad & $\begin{array}{l}\text { "\#Quédate } \\
\text { en casa" }\end{array}$ & $\begin{array}{l}\text { Representación de la muerte } \\
\text { en la puerta de una casa, } \\
\text { acompañada por el Covid-19. }\end{array}$ & $\begin{array}{l}\text { Con un grito de terror, los inte- } \\
\text { grantes de una familia piden que } \\
\text { la muerte y el virus se alejen. Usa } \\
\text { signos de admiración para evi- } \\
\text { denciar el énfasis de la acción. }\end{array}$ \\
\hline Corrupción & “i8 años!” & $\begin{array}{l}\text { El expresidente Correa } \\
\text { encarna al virus que provocó } \\
\text { la pandemia: grita por la } \\
\text { sentencia que recibió. Su } \\
\text { corona se ha caído y está con } \\
\text { verde flex, que utilizó durante } \\
\text { su campaña. }\end{array}$ & $\begin{array}{l}\text { Es elocuente en la comparación } \\
\text { de Rafael Correa con el virus; } \\
\text { es una caricatura que hace } \\
\text { reflexionar la posición de Bonil } \\
\text { frente al ex presidente quien } \\
\text { emprendió una acción judicial } \\
\text { por los contenidos de sus } \\
\text { trabajos. }\end{array}$ \\
\hline Tecnología & $\begin{array}{l}\text { ¿Cuántas } \\
\text { fake news } \\
\text { consumiste hoy? }\end{array}$ & $\begin{array}{l}\text { Aparece un tacho lleno de } \\
\text { noticias falsas que son } \\
\text { descargadas desde el móvil. }\end{array}$ & $\begin{array}{l}\text { Formula una pregunta para que } \\
\text { el lector responda, quizá desde } \\
\text { su experiencia. }\end{array}$ \\
\hline
\end{tabular}

Nota: Elaboración propia, basada en los ejemplares del diario

El Universo (13/III/2020-10/IV/2020).

En este estudio también se identificaron los actores que cumplen la función de personificación en los trabajos: un carácter de diversidad fue empleada para ilustrar los contenidos, para que interactúen con la realidad presentada. Hombres y mujeres adultos; ancianos, niños, jóvenes, políticos (Rafael Correa), funcionarios de gobierno, diplomáticos, tuiteros, así como representaciones del virus, el teléfono, el teclado de un computador, los pacientes enfermos y la muerte. La originalidad de las representaciones permitió que se facilite la comprensión del hecho y que se lleguen a conclusiones. 
Los aspectos gestuales y de expresión cumplieron un rol decisivo en las viñetas, ya que evidenciaron el énfasis del personaje frente a la temática, por eso fue una de las claves que se observaron en el análisis: simbolizaron los sentimientos de quienes actuaron en los dibujos y la posición sobre determinados aspectos. Del mismo modo, representaron afecto, manipulación, regulación, ilustración, interrogación o admiración. Bonil recreó en los rostros dibujados sentimientos de seriedad, indignación, molestia, conformismo, mal humor, angustia, alegría, amenaza, malestar, esfuerzo, asombro, tranquilidad, tristeza, pánico y desprecio. Cada gesto y expresión llevó consigo simbolismo y significación, facilitándose la interpretación de lo visual. La trama se desenvolvió en escenarios cotidianos para las personas en medio de su confinamiento: la sala de la casa, la clínica, la oficina, la cocina, la calle, el teletrabajo, frente al televisor, el cementerio.

Para la composición, se usó el plano general para abarcar el cuadro completo de la acción. Cabe destacar que las caricaturas fueron presentadas a todo color y en escala de grises.

Figura 7

Caricatura de Bonil: "Manejo de información"
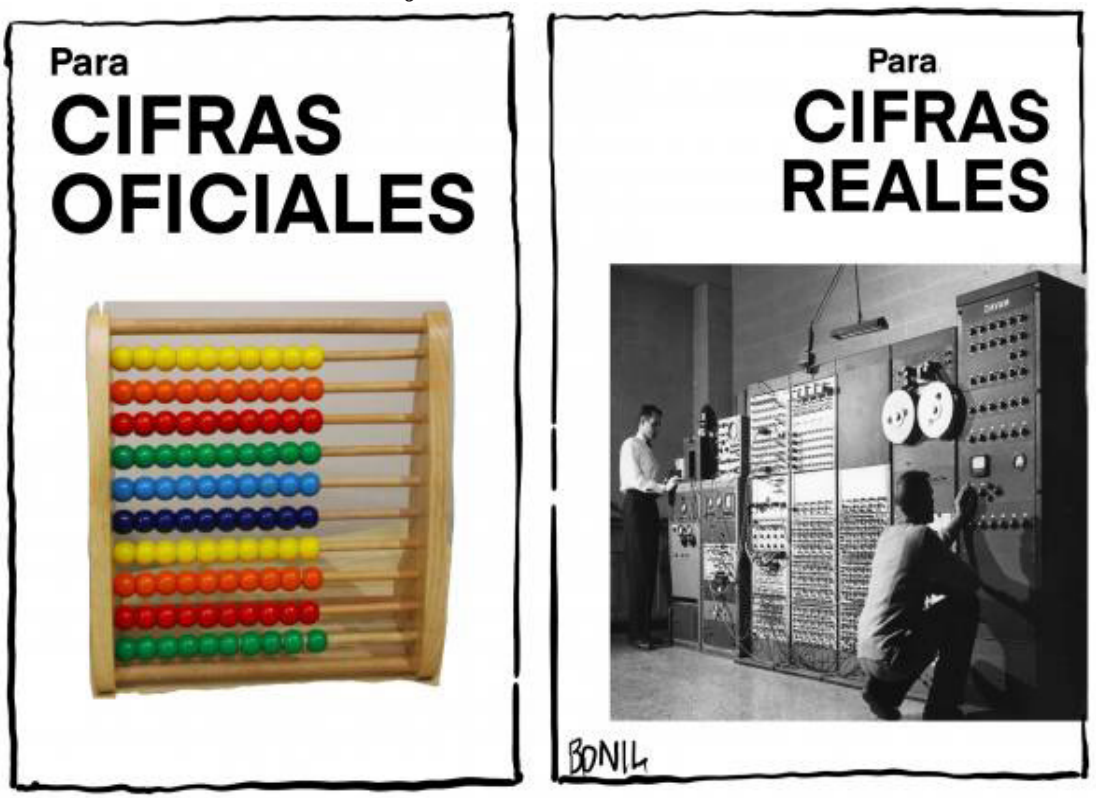

Nota: Diario El Universo (5/IV/2020). 
El título (así como los códigos icónicos, el lenguaje verbal, los actores, sus gestos y expresiones, los ambientes, el plano y el color) permitieron la construcción de la metáfora visual que es la transmisión de un mensaje utilizando recursos gráficos que orientan a la opinión pública hacia los hechos. Por ejemplo, en la Figura 7, la confrontación de las cifras oficiales frente a los datos reales hizo cuestionar el manejo gubernamental de las estadísticas. Para ahondar más en la polémica, Bonil muestra un ábaco (que refleja lo artesanal de sus resultados oficiales, que considera un número pequeño de contagios) y un centro de almacenamiento de la información (data center) que ofrecería unos resultados más completos y confiables.

Como se puede apreciar, los atributos cuantitativos y cualitativos permitieron a Bonil explicar fácilmente los hechos a los lectores. Es importante destacar que la calidad de información obtenida dependió, en gran medida, de la rigurosidad de la aplicación de las matrices, del cuidado en las observaciones, de la precaución al identificar la intencionalidad de los trabajos, del análisis de lo que se pretendió representar mediante lo verbal e icónico, así como del posicionamiento del autor frente a los temas.

\subsection{Análisis crítico del discurso}

Estos hallazgos guardan ciertas similitudes con los datos provenientes del análisis de contenido, pero solo son de forma: coincidieron en aspectos como el temático y los actores; pero, resulta claro que las dos técnicas tienen una metodología y un fin distinto. Para el ACD se usan otros criterios, tales como el micro, que pretende poner en evidencia la fortaleza del lenguaje, el entorno discursivo y el grado de interacción verbal. A su vez, el macro es la escenificación de poder, dominación y desigualdad, observándose el conjunto de interrelaciones de los integrantes de grupos, las estructuras sociales, sus acciones y procesos. En ese sentido, el análisis crítico del discurso fue un ejercicio de profundización de lo que representan las caricaturas frente a la realidad social.

Como se mencionó en el anterior párrafo, el nivel micro se realizó a partir de tres categorías: 


\subsubsection{Uso del lenguaje}

Las caricaturas exhibieron un estilo coloquial, directo, claro, sencillo y concreto; las exclamaciones e interrogaciones tuvieron una intencionalidad envolvente; privilegió lo visual para aquellos temas que se explicaban. Por ejemplo, en la Figura 8, la interacción de un médico con su paciente y su esposa: el galeno emplea un juego de palabras para señalar un caso excesivo de aprovisionamiento de víveres.

Figura 8

Caricatura de Bonil (sin título)

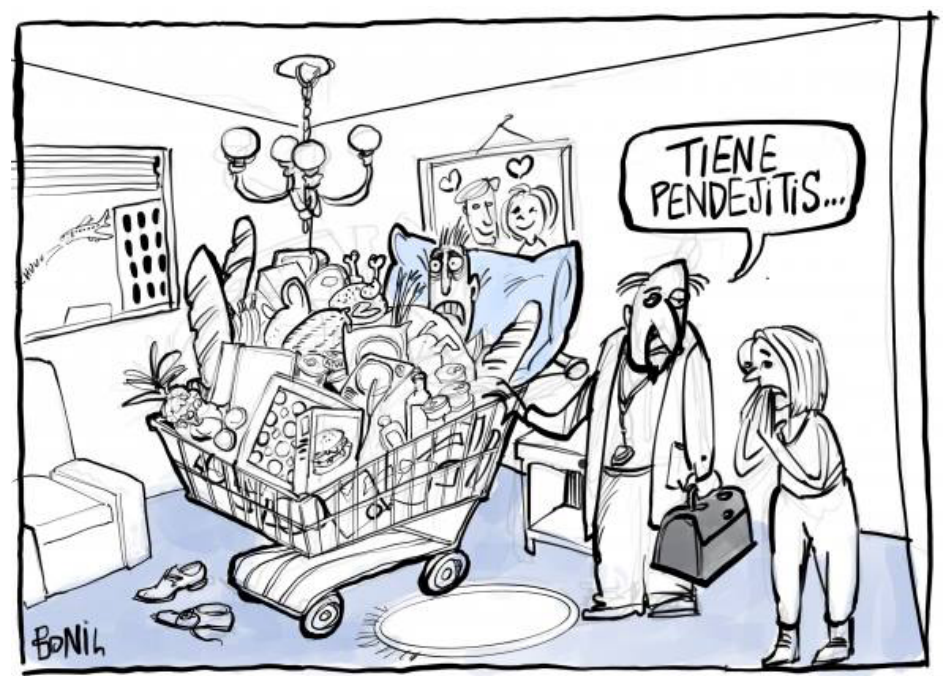

Nota: Diario El Universo (13/III/2020).

\subsubsection{Entorno discursivo}

Se identifica la vida cotidiana de los actores que se representan en las viñetas, mostrándose escenas hogareñas, en las calles, en las clínicas; durante el teletrabajo, interacciones familiares, tiempo de ocio frente al móvil y consumo de contenidos falsos; la pista de un aeropuerto bloqueada, las evasivas de un diplomático que no puede justificar sus versiones sobre la emergencia, dadas en España; la solicitud de divorcio que le hace una mujer a su esposo cuando surgió el COVID-19, entre otros. 


\subsubsection{Interacción verbal}

Una de las fortalezas de la propuesta de Bonil es propender al diálogo entre los actores que aparecen en sus trabajos, como es el caso de la problemática familiar, relacionado con el maltrato contra la mujer y el consecuente pedido de divorcio (Figura 9).

\section{Figura 9}

Caricatura de Bonil ("Quiero el divorcio")

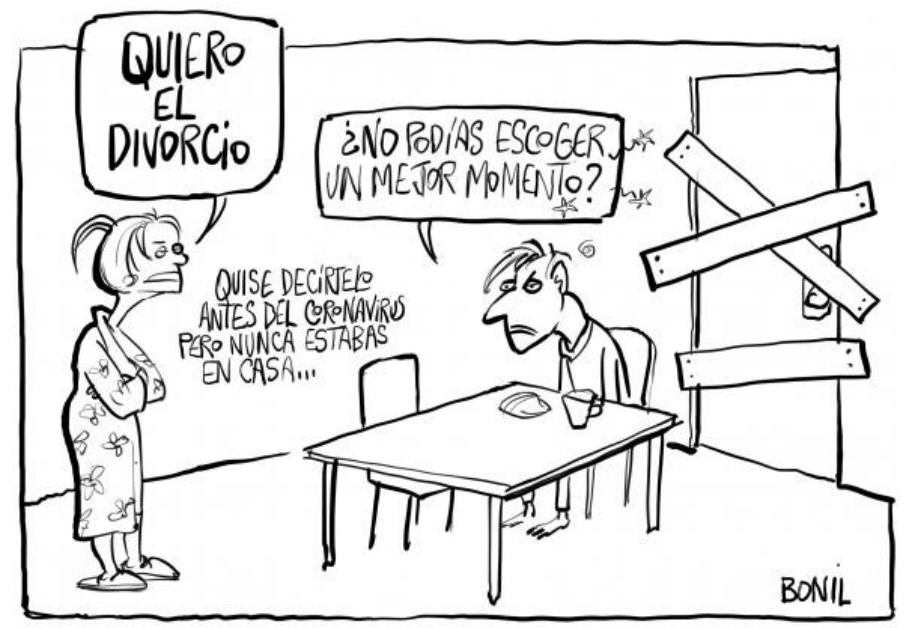

Nota: Diario El Universo (19/III/2020).

El nivel macro, fue analizado desde tres instancias:

\subsubsection{Poder}

Representado por un médico que ordena a sus pacientes tomar precauciones frente al virus; la mujer que, con autoridad, le dice al marido que esperó a que estuviera en casa para que autorice el divorcio; el virus frente al planeta; la muerte y el virus que amenazan a las familias.

\subsubsection{Dominación}

Expresado por la esposa que exige el divorcio a su esposo, en tiempos de Covid-19; el virus que sin una vacuna mata millones de personas (“\#Quédate 
en casa", 17/III/2020); la dueña de una farmacia que increpa al comprador por querer automedicarse (“¡Deme cloroquina!”, 27/III/2020); la alcaldesa de Guayaquil, que dispone no permitir el aterrizaje de aviones para evacuar ciudadanos extranjeros (Figura 5).

\subsubsection{Desigualdad}

Las familias que están en casa frente al paso del virus que trae la muerte; la tripulación y los extranjeros que esperan el aterrizaje del avión para evacuarlos hacia España (Figura 6); la mujer y sus dos hijos frente a las agresiones del marido y padre (Figura 9); los ciudadanos que no confían en las cifras oficiales porque el número de contagiados y muertos es mayor que lo anunciado desde lo gubernamental (Figura 7).

Por último, están las interrelaciones entre integrantes de un grupo (familia, amigos, compañeros de teletrabajo, alcaldesa, tripulantes, médico, pacientes, farmacéutica, enfermo, tuitero, virus, muerte); la definición de la estructura social (pobres, ricos, empleados, desempleados, estudiantes, profesores, médicos, pacientes) y las acciones-procesos (llamado por protección frente a la violencia de género. ${ }^{2}$ Estas tres consideraciones son importantes para contextualizar la forma en que la sociedad es retratada en las caricaturas.

\section{Discusión de resultados}

La investigación demostró que los abordajes utilizados por el caricaturista Bonil visibilizaron multiplicidad de situaciones relacionadas con la pandemia; que el tratamiento del virus no se lo realizó solamente desde el campo de la salud. La aplicación de las matrices (de análisis de contenido y de discurso) pusieron énfasis en la observación de ciertos detalles que pudieron pasar inadvertidos en los lectores, demostrándose que una caricatura es un contenido lejano de lo artesanal, que puede ser elaborado con rigurosidad, que transmite intencionalidad y carga ideológica del autor-medio.

2. Precisamente, el diario El Universo (12/IV/2020) señala que durante la cuarentena 235 mujeres denunciaron ante las autoridades judiciales haber sido víctimas de maltrato por sus cónyuges, confirmándose la representación gráfica realizada por Bonil (Figura 9). 
Para la discusión de resultados se usaron tres tablas: cuadro relacional entre metáfora visual y discurso (Tabla 2); poder, dominación y desigualdad ejercida por los actores (Tabla 3) y carga intencional presentada en el humor gráfico (Tabla 4). Si bien la Tabla 1 realiza un balance general de los trabajos analizados, en este epígrafe se particularizan de acuerdo con criterios específicos y se recogen elementos distintos advertidos en los contenidos que necesitan analizarse para facilitar su comprensión.

\section{Tabla 2}

Cuadro relacional entre metáfora visual y discurso

\begin{tabular}{|c|c|c|}
\hline \multirow{2}{*}{ TÍTULO } & ANÁLISIS DE CONTENIDO & ACD \\
\hline & Metáfora visual & Discurso \\
\hline $\begin{array}{l}\text { "Por qué } \\
\text { esperamos para } \\
\text { despertar" }\end{array}$ & $\begin{array}{l}\text { Usa iniciales (QEPD: Que en Paz } \\
\text { Descanse) y las utiliza para dar otro } \\
\text { mensaje: Por Qué Esperamos Para } \\
\text { Despertar (QEPD). }\end{array}$ & $\begin{array}{l}\text { Alerta, usando una exclamación } \\
\text { con tipografía empleada para } \\
\text { lo fúnebre, del tiempo perdido } \\
\text { que no se recuperará frente a la } \\
\text { emergencia. }\end{array}$ \\
\hline $\begin{array}{l}\text { "Las verdaderas } \\
\text { cifras las } \\
\text { conozco yo..." }\end{array}$ & $\begin{array}{l}\text { El virus sentado, impone su verdad } \\
\text { sobre las cifras reales de contagios del } \\
\text { Covid-19, frente a las especulaciones de } \\
\text { datos oficiales de contagios y muertes. }\end{array}$ & $\begin{array}{l}\text { Expresa una terrible realidad: } \\
\text { solo el virus conoce el número } \\
\text { exacto de víctimas. }\end{array}$ \\
\hline Sin título & $\begin{array}{l}\text { Desproporción en la producción y con- } \\
\text { sumo de fake news; crece exponencial- } \\
\text { mente como el virus y su fin es como el } \\
\text { de los fallecidos, una fosa común por la } \\
\text { falta de espacio para sepultarlos. }\end{array}$ & $\begin{array}{l}\text { Un hombre lleva una carretilla } \\
\text { llena de noticias falsas y la } \\
\text { arroja sobre un teclado de } \\
\text { computadora que se asemeja } \\
\text { a una fosa común. }\end{array}$ \\
\hline
\end{tabular}

Nota: Elaboración propia, basada en los ejemplares del diario

El Universo (13/III/2020-10/IV/2020).

La clave para la discusión de los hallazgos fue cruzar las variables que se encuentran en las columnas de las matrices que sirvieron para el análisis. Es así que la explicación de las relaciones entre metáfora visual (el nivel de representación y simbolismo que deja la caricatura en la persona que la aprecia) y discurso (unión de iconicidad, lenguaje verbal, forma, color, intencionalidad de la unión de lo gráfico con la palabra) se realiza usando tres viñetas sobre diferentes ejes temáticos (ver Figura 2). Así, se recurre a tres ejemplos y se propone una caricatura sobre la importancia del distanciamiento social (Figura 10). 
Figura 10

Caricatura de Bonil "El Distanciamiento social necesario"

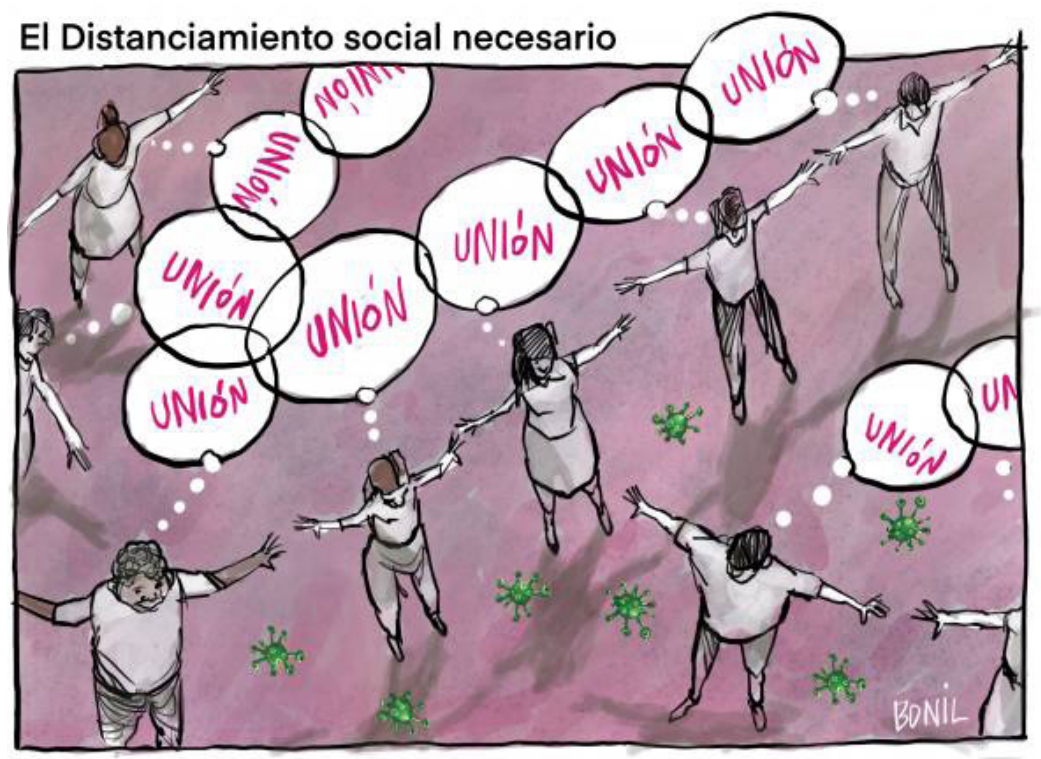

Nota: Diario El Universo (31/III/2020).

La imagen que ocupa la caricatura de Bonil ("Por Qué Esperamos Para Despertar, 28/III/2020) corresponde a las letras iniciales de la inscripción de una lápida ("Que En Paz Descanse"). Cada una se particularizó para modificar el sentido, pero se antepuso la palabra "por" para presentarla de esta forma: Por Qué Esperamos Para Despertar. Esta acción corresponde a la metáfora visual, mientras el discurso es un llamado de atención para una oportuna atención de la emergencia.

La siguiente, motivo de estudio es elocuente visual y discursivamente; el virus exclama que es el único que conoce la realidad de los contagios y de las víctimas; sentado con comodidad parece burlarse; su leyenda constituye la afirmación de una tragedia mundial ("Las verdaderas cifras las conozco уо...", 25/III/2020). 
Tabla 3

Poder dominación y desigualdad ejercida por los actores

\begin{tabular}{|c|c|c|}
\hline \multirow{2}{*}{ TíTULO } & $\begin{array}{l}\text { ANÁLISIS DE CONTE- } \\
\text { NIDO }\end{array}$ & ACD \\
\hline & Actores & Poder, dominación, desigualdad \\
\hline $\begin{array}{l}\text { "iOtra vez vienes } \\
\text { oliendo a } \\
\text { alcohol!" }\end{array}$ & $\begin{array}{l}\text { Dos manos } \\
\text { (marido y mujer) }\end{array}$ & $\begin{array}{l}\text { La mano que se asemeja a la mujer, ejerce } \\
\text { "poder" sobre el esposo usando el reclamo; } \\
\text { la "dominación" ejerce la esposa frente a una } \\
\text { acción: otra vez con olor a alcohol; el } \\
\text { hombre, por su estado, se encuentra en } \\
\text { "desigualdad", no dice nada, solo calla. }\end{array}$ \\
\hline "Fiebre viral" & $\begin{array}{l}\text { Teléfono, consejos, } \\
\text { noticias falsas y bullying }\end{array}$ & $\begin{array}{l}\text { El "poder" y la "dominación" están en los } \\
\text { consejos, noticias falsas y bullying; en } \\
\text { "desigualdad" las personas frente a la } \\
\text { cantidad de mensajes no veraces. }\end{array}$ \\
\hline $\begin{array}{l}\text { "Hacen tonteras. } \\
\text { Manejan mal la } \\
\text { crisis. ¡Dejen a } \\
\text { los expertos!" }\end{array}$ & Tuitero & $\begin{array}{l}\text { Ejerce el "poder" con su opinión en las redes } \\
\text { sociales; la "dominación" se expresa cuando } \\
\text { intenta hacer prevalecer su opinión frente a } \\
\text { la de los demás; y la gente se encuentra en } \\
\text { desigualdad porque no puede expresar sus } \\
\text { criterios. }\end{array}$ \\
\hline Sin título & $\begin{array}{l}\text { Hombre, carretilla y } \\
\text { fosa común }\end{array}$ & $\begin{array}{l}\text { "Poder": los contenidos falsos en la fosa } \\
\text { común; "dominación": el ciudadano que } \\
\text { desecha lo que no sirve; "desigualdad": de } \\
\text { las fake news frente a la determinación de } \\
\text { sepultarlas en una fosa común. }\end{array}$ \\
\hline
\end{tabular}

Nota: Elaboración propia, basada en los ejemplares del diario

El Universo (13/III/2020-10/IV/2020).

Con frecuencia, la prevalencia del poder, la dominación y la desigualdad provocan confrontación entre actores y no permite el diálogo. ${ }^{3}$ Todas las caricaturas propuestas por Bonil, tienen estas características. El primer caso (Figura 3) emplea personajes a dos manos (marido y mujer); ella ejerce el poder cuando le increpa a su marido por llegar oliendo a alcohol; la dominación en el núcleo familiar se impone desde lo femenino; la desigualdad identifica al marido que no oculta que la acusación es verdadera.

En la segunda saltan a escena un teléfono y los íconos de las fake news, los consejos y el bullying; la sobrecarga de contenidos hace que el móvil se sature y se descargue en un tacho de basura. En este caso, el poder y la dominación

3. De la observación del comportamiento de estas dos variables (poder, dominación y desigualdad; actores) se enfoca el apartado siguiente de conclusiones. 
se expresan en el exceso de contenidos que saturan la capacidad del aparato electrónico que muestra su impotencia y no tiene más opción que desecharlos (Figura 11). El título es elocuente: la fiebre se asemeja a la producida por la enfermedad y lo viral guarda relación con la naturaleza del COVID-19.

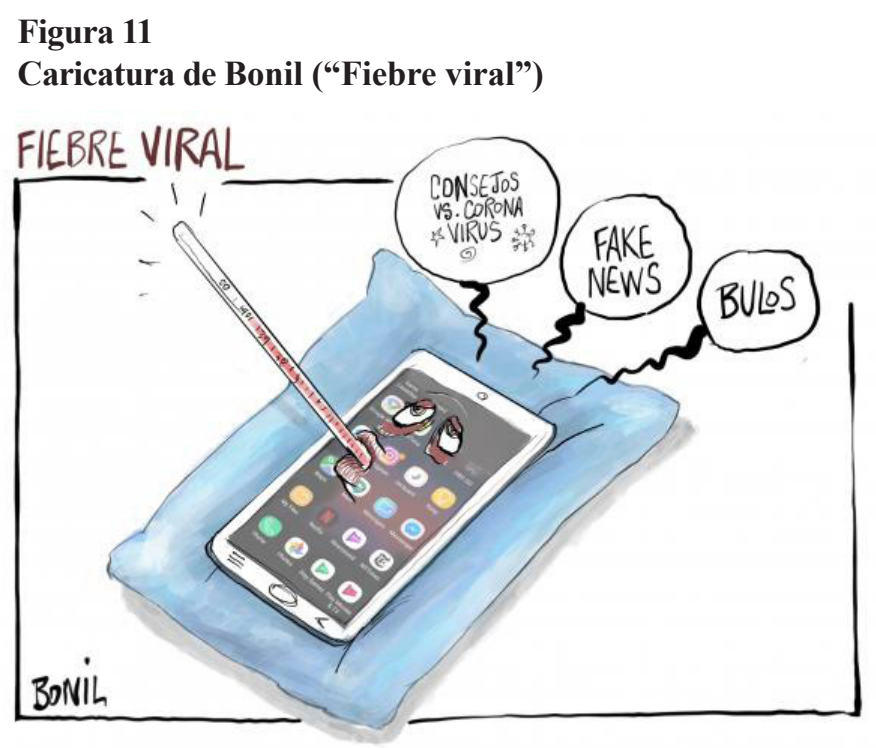

Nota: Diario El Universo (18/III/2020).

En la tercera ("Hacen tonteras. Manejan mal la crisis. ¡Dejen a los expertos!", 26/III/2020) se pone en escena un nuevo actor en el escenario de la opinión: un tuitero que con sus comentarios sobre el manejo de la crisis evidencia el poder y pretende dominar a la sociedad. La desigualdad radica en que no todos tienen acceso a las redes sociales, por lo tanto, no pueden opinar sobre sus dificultades por esta vía. Así, la caricatura que aparece como ilustración de la tabla es una fosa común a donde van a parar los contenidos falsos. 
Tabla 4

Carga intencional presentada en el humor gráfico

\begin{tabular}{|c|c|c|}
\hline \multirow{2}{*}{ Título } & ANÁLISIS DE CONTENIDO & ACD \\
\hline & Discurso & Dominación \\
\hline $\begin{array}{l}\text { "\#Quédate en } \\
\text { casa" }\end{array}$ & $\begin{array}{l}\text { El virus y la muerte acechan; la gente grita } \\
\text { desde dentro de una casa para que se } \\
\text { alejen. }\end{array}$ & $\begin{array}{l}\text { El poder de la enfermedad que } \\
\text { lleva a millones de personas a } \\
\text { la muerte. }\end{array}$ \\
\hline $\begin{array}{l}\text { “¿Al estilo } \\
\text { Jaime... } \\
\text { Vargas?" }\end{array}$ & $\begin{array}{l}\text { El cierre de la pista del aeropuerto de } \\
\text { Guayaquil ordenado por la alcaldesa. }\end{array}$ & $\begin{array}{l}\text { El poder político frente a cientos } \\
\text { de extranjeros que quieren } \\
\text { retornar a sus países. }\end{array}$ \\
\hline Sin título & $\begin{array}{l}\text { Ex presidente Correa responsable por la } \\
\text { crisis económica. }\end{array}$ & $\begin{array}{l}\text { La decisión que tuvo en sus } \\
\text { manos, al ejercer la Presidencia } \\
\text { de Ecuador, para ahorrar los } \\
\text { recursos y afrontar (de mejor } \\
\text { manera) una emergencia } \\
\text { como la actual. }\end{array}$ \\
\hline “¡8 años!” & $\begin{array}{l}\text { El ex presidente Correa encarna al virus } \\
\text { que provocó la pandemia: grita por la } \\
\text { sentencia que recibió; su corona se ha } \\
\text { caído. Está con verde flex, color que } \\
\text { utilizó durante su campaña. }\end{array}$ & $\begin{array}{l}\text { Del Poder Judicial frente al } \\
\text { acusado de corrupción. }\end{array}$ \\
\hline
\end{tabular}

Nota: Elaboración propia, basada en los ejemplares del diario

El Universo (13/III/2020-10/IV/2020).

Para concluir la discusión de resultados, la Tabla 4 presenta opciones del tratamiento de las caricaturas. Como se puede apreciar, se escogieron dos caricaturas que aparecen juntas, con una carga grande de intencionalidad, teniendo como protagonista al ex presidente de Ecuador, Rafael Correa: en la Figura 12 luce una corona de rey (asociada al autoritarismo que profesó sobre su mandato), una lengua larga (porque nunca dejó de atacar a sus opositores, incluido Bonil). En la Figura 13 prevalece el color verde que es el mismo con que se representa al virus y a su agrupación política (Alianza País, hoy Revolución Ciudadana). 
Figuras 12 y 13

Caricaturas e intención ("Fue la fiebre derrochadora" y "¡8 años!")
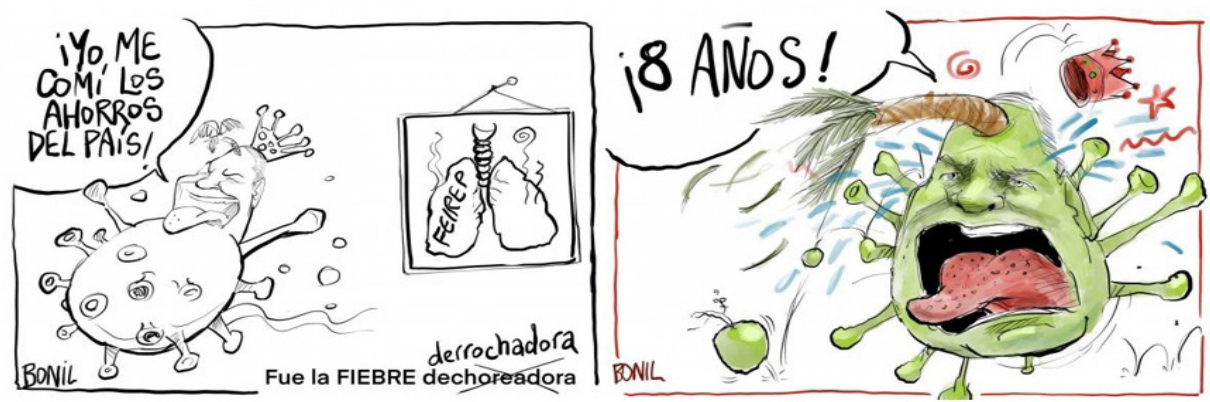

Nota: Diario El Universo (24/III/2020 y 8/IV/2020).

La intención del autor es responsabilizarlo por la crisis sanitaria (provocada por la carencia de insumos médicos y equipamiento) al gastarse el dinero en tiempos de bonanza (Figura 12) y en destacar la sentencia que lo condenó a ocho años de prisión por el caso de sobornos que coincide con la etapa de emergencia sanitaria (Figura 13).

\section{Conclusiones}

Las caricaturas publicadas ofrecen diversidad de abordajes del tema de la pandemia por el COVID-19. Buscan, por una parte, generar conciencia sobre la trascendencia del cuidado personal, la importancia de quedarse en casa para no ser contagiado y dejar de lado lo social, mientras dura la emergencia sanitaria como mecanismo para salvar vidas. Por otro lado, identifican aspectos como la falta de transparencia gubernamental en el manejo de las cifras; los casos de corrupción que imperan en medio del confinamiento; cómo la tecnología ha pasado en primer plano en la vida de las personas por la cantidad de contenidos que se consumen, la mayoría falsos; y vincula el poco equipamiento y falta de insumos médicos con el despilfarro del gobierno de Rafael Correa, a quien le personifica icónicamente con el virus.

El análisis de contenido determinó que el humor gráfico (con el que fueron contadas las historias de la crisis) contribuyó a la generación de opinión pública de las audiencias. La aplicación de la matriz de análisis identificó todos los aspectos del contenido (tema, título, discurso, actores, etc.) y contextua- 
lizaron lo que Bonil quiso referenciar a la gente, así como el uso de aspectos de interés colectivo que necesitan aparecer en los medios para que la sociedad crea que existen. Los resultados (si bien identificaron detalles de los trabajos se convirtieron en relevantes para dimensionar la crisis sanitaria) fustigaron al poder y llamaron la atención frente a la transparencia de la información, la no automedicación, la lucha contra los actos de corrupción, el uso responsable de las tecnologías y la responsabilidad ciudadana frente a la pandemia.

El ACD por su parte, determinó cómo el uso del lenguaje, el discurso y la interacción verbal permitieron comprender cómo una caricatura puede incidir en la opinión de las personas y forma un criterio sobre su realidad próxima. Fueron trascendentes (y aportaron para la comprensión de los hechos) el poder, la dominación y la desigualdad: tres instancias que intervienen juntas en la construcción de la sociedad, atadas por un mismo hilo conductor que desnuda su modus operandi en la prevalencia de la hegemonía. Asimismo, el ACD identificó la forma en la que se complementan los miembros de un grupo, de qué manera se unifican acciones y procesos, comprendiéndose la estructura social como el escenario en el que se entretejen las interrelaciones.

Por último, se demostró que para este tipo de investigaciones sí pueden combinarse el análisis de contenido y el análisis crítico del discurso. El primero entrega información referente a los criterios que reúnen los contenidos y cómo estos son visualizados por los lectores. En cambio, el segundo identifica espacios de poder y dominación como parte de un sometimiento discursivo que hace evidente la desigualdad social. Así, entrega respuestas (con claridad) de las actuaciones frente a la crisis.

\section{Fuentes consultadas}

Ahumada, Y. (2019). El humor gráfico como medio de opinión pública durante la crisis de 2001 en Argentina. Universidad de Palermo.

Antezana, L. (2009). Política en caricaturas y fotomontajes de la prensa chilena: risas y sonrisas. Mapocho, 65, 135-147. 
Arias, E. (2008). El muy serio arte del humor. Ronderos, Maria Teresa (2007). 5 en humor. Bogotá: Aguilar (pp. 411) [Reseña]. Revista de Estudios Sociales, 30, 110-112. http://www.scielo.org.co/scielo.php?script=sci_arttext\&pid=S0123-885X2008000200012\&lng=en\&tlng=es

Borregales, Y. (2016). 70 años de humor en Venezuela. Tiempo y Espacio, 26(65), 167-169. http://ve.scielo.org/scielo.php?script=sci_arttext\&pid=S1315-94962016000100012\&lng=es\&tlng=es

Borregales, Y. (2017). Importancia de la caricatura como fuente de conocimiento histórico. Tiempo y Espacio, 27(68), 111-128. http://ve.scielo.org/ scielo.php?script $=$ sci_arttext\&pid=S1315-94962017000200007\&ln$\mathrm{g}=\mathrm{es} \&$ tlng=es

Bravo, J. (2012). La Rosa de los vientos. Casa de la Cultura núcleo de Chimborazo.

Bravo, J., Galindo, F., \& Bravo, S. (2019a). Leonidas Proaño: orientación periodística más allá de lo religioso y educativo. Revista ComHumanitas, 10(2). https://doi.org/10.31207/rch.v10i2.200

Bravo, J., Larrea, C., Ruales, R., \& Bravo, C. (2019b). La acción comunicativa en los pueblos indígenas de Chimborazo como herramienta para el cambio social. Brazilian Journal of Development, 5(3), pp. 25642575 .

Conde, L. (2005). El humor gráfico en la prensa española. Cuadernos de periodistas, 3, 113-123. http://www.cuadernosdeperiodistas.com/pdf/ Cuadernos_de_Periodistas_3.pdf

Díaz-Bravo, L., Torruco-García, U., Martínez-Hernández, M., \& Varela-Ruiz, M. (2013). La entrevista, recurso flexible y dinámico. Investigación en Educación Médica, 2(7), 162-167. https://www.redalyc. org/pdf/3497/349733228009.pdf

Fernández, A. (2015). Caricatura política, razones y emociones. Razón y palabra, 19(89), 212-234. https://www.revistarazonypalabra.org/index. php/ryp/article/view/236 
Fernández, F. (2002). El análisis de contenido como ayuda metodológica para la investigación. Revista de Ciencias Sociales, 2(96), 35-53. https:// www.revistacienciassociales.ucr.ac.cr/images/revistas/RCS96/03.pdf

Gómez, M., Deslauries, J., \& Alzate, M. (2010). Cómo hacer tesis de maestría y doctorado: investigación, escritura y publicación. Colección Educación y Pedagogía.

González-Domínguez, C. (2017). Líder de opinión y opinión pública. Hacia una reflexividad epistemológica de los conceptos. Revista Mexicana de Opinión Pública, 22, 15-32. http://www.scielo.org.mx/scielo.php?script=sci_arttext\&pid=S2448-49112017000100015\&lng=es\&tlng=es

Gronemeyer, M. (2003). El periodismo como vocación y opción creyente. Teología y vida, 44(1), 48-67. https://dx.doi.org/10.4067/S004934492003000100003

Hegel, G. (2006). Phénoménologie de l'esprit. Vrin.

Hernández, O. (1995). Culturas y educación: rupturas y encuentros en la reelaboración cultural. Revista de Ciencias Sociales, 69, 7-19.

Hurtado, J. (2010). Metodología de la investigación. Guía para la comprensión holística de la ciencia. Ediciones Quirón.

Lemos, H. (2011). La capacidad retórica del humor gráfico: la "columna gráfica”. Revista de Comunicación Vivat Academia, 117(XIV), 11941206. http://www.vivatacademia.net/index.php/vivat/article/view/120

Monje, C. (2011). Metodología de la investigación cuantitativa y cualitativa. Universidad Surcolombiana.

Muñiz, C. (2017). Comunicación y opinión pública. Cuadernos.info, 40, 10 13. https://scielo.conicyt.cl/pdf/cinfo/n40/0719-367X-cinfo-40-00010.pdf

Navarro, P., \& Díaz, C. (1994). Análisis de contenido. En J. Delgado \& J. Gutiérrez (Coords.), Métodos y técnicas cualitativas de investigación en ciencias sociales (pp. 177-224). Síntesis. 
Organización de las Naciones Unidas para la Educación, la Ciencia y la Cultura, UNESCO. (2007). Model curricula for journalism education. Colección de la UNESCO sobre los estudios de Periodismo. http:// www.unesco.org/new/es/communication-and-information/resources/ publications-and-communication-materials/publications/full-list/model-curricula-for-journalism-education

Rincón, O. (2017). Del periodismo domesticado al periodismo bastardo y DJ. Alcance, 6(12), 6-25.http://scielo.sld.cu/scielo.php?script=sci_arttext\&pid=S2411-99702017000100002\&lng=es\&tlng=es

Rivera-Betancur, J. (2008). Nuevos desafíos para un nuevo periodismo. Palabra Clave, 11(2), 153-154. http://www.scielo.org.co/scielo.php?scrip$\mathrm{t}=$ sci_arttext\&pid=S0122-82852008000200001\&lng=en\&tlng=es

Rodríguez-Pastene, F., González, C., \& Messenet, F. (2019). Sátira política en las elecciones de 1935 y de 2016. Estudio comparativo de representaciones sociales femeninas en Topaze y The Clinic. Comunicación y medios, 28(39), 26-38. https://scielo.conicyt.cl/pdf/cym/ v28n39/0719-1529-cym-28-39-00026.pdf

Salinas, P., \& Cárdenas, M. (2009). Métodos de investigación social. Ediciones Ciespal.

Siegel, L. (2017, Enero 13). In the story of Trump, there is no story. Columbia Journalism Review. http://www.cjr.org/special_report/trump_story_narrative_press_co nference.php

Valencia, V. (2012). Revisión documental en el proceso de investigación. Universidad Tecnológica de Pereira.

Van Dijk, T. (2016). Análisis crítico del discurso. Revista Austral de Ciencias Sociales, 30, 203-222.

Zavaleta, R. (2000). Un sueño semiótico hacia la caricatura. Punto Cero, 5(1), 52-53. http://www.scielo.org.bo/scielo.php?script=sci_arttext\&pi$\mathrm{d}=\mathrm{S} 1815-02762000000200012 \& \operatorname{lng}=\mathrm{es} \& \operatorname{tn} \mathrm{ln}=\mathrm{es}$ 